\title{
Movies for the Ears to Come
}

\author{
Massimiliano Tonelli \\ Independent composer \\ St. di Fagnano 761122 Pesaro, Italy \\ tonelli.conservatorio@gmail.com
}

\section{INTRODUCTION}

Acousmatic music is not a new form of art. However, the development of low cost solutions for digital audio manipulation and multichannel-3D audio opens new possibilities.

\section{ACOUSMATIC MUSIC}

Acousmatic refers to a kind of music based on fixed media. Even if today the capability of recording a sound is taken for granted, it is indeed a conceptually deep act. Recording a sound can detach it from its context and disconnect to its source cause. This creates an ambiguity, as a consequence of obscuring the sound own identity, which gives space for the artistic expression. Art often arises whenever elements are used to convey a meaning beyond their objectiveness.

Acousmatic music is rooted in Pierre Shaffer's "music concrète", where the distinction between sound produced by a musical instrument and any sound (human, environmental, mechanical etc.) is abolished. Noise, interpreted in a wide sense, becomes a first class element of music. Any sound, as for example a train passing by, can have its own beauty and expressiveness.

It is probably worthy to note that, paradoxically, classical compositions based on usual musical instruments can be more abstract in nature than experimental music based on noises. Classical music requires a high level of abstraction: a codified representation and a specialised skill, based on years of training, to transform these symbols into meaningful gestures. Therefore, it is somewhat surprising that classical music is naturally considered more "acceptable" than others. The "music concrète" is, by construction, more concrete.

Unfortunately, the simple tools that Shaffer had at the time to manipulate audio recordings (the main technique was to create audio loops), did not permit to explore many of the possibilities of its theorisation. Today, the processing power of general-purpose computer allows composers complex and inexpensive digital audio processing.

\subsection{Created and discovered sounds}

Music is usually produced by mechanical or electro-acoustic devices. A less usual way, as described above, is to create music by using recorded sounds.

Therefore, it is possible to distinguish between two categories: "sounds that are created" and "sounds that are discovered". Obviously, there is no limitation in the interactions between the two approaches.

A recording allows the composer to fix a sound and to explore its structure and expressiveness. Often, just by slowing it down, several interesting features emerge. The sound assumes a different communicative power. The composer that follows this approach, can be thought as an explorer in search of hidden landscapes inside a sonic structure.

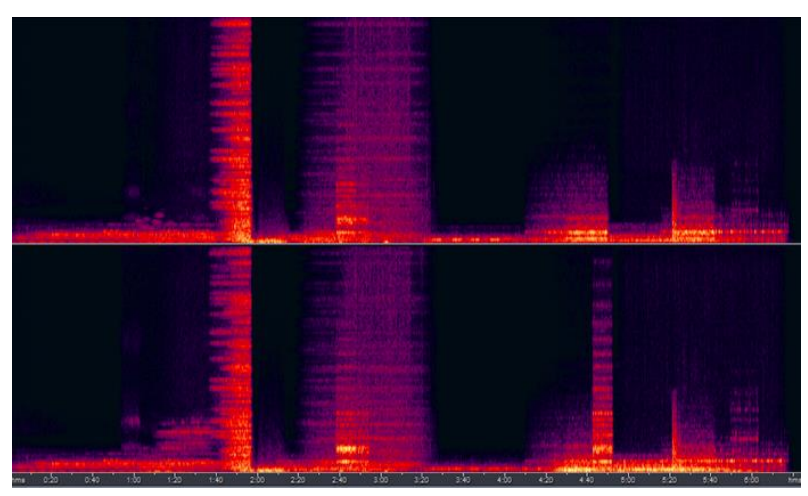

Figure 1: Spectrogram of the composition 'Abbasso Cadorna'.

\subsection{Space-vision, time-music}

Images have the predominance in our contemporary communication. A message can be quickly conveyed by an image. As Chion says, 
images and sound together create something more than the summation of the two components.

However, in this encounter something can be lost. Sound can be hidden in the flow of images. How often are we fully conscious of what is happening in a soundtrack? An important fact that Chion highlights, is that images are linked to the representation of space while sounds, that create a sense of temporal vectorisation, are linked to time. Sounds manifest events in time.

It is interesting to note how the habit of sitting comfortably and listen to recorded music, a very popular hobby in the past, is nowadays very rare. Probably in our contemporary life, schedules are too tight for this. Stereophonic music could not keep the pace with space. Usual stereophonic systems can create a very approximated spatial reconstruction. However, technologies that can provide far more convincing results exit. Ambisonics, for instance, offers a very realistic spatial reconstruction of an acoustic gesture.

I had the chance to see the reaction of people, with no specific music training, listening to ambisonics recordings and compositions and I was impressed by how they enthusiastically described their experience as "movies for the ears".

\section{ABBASSO CADORNA}

Abbasso Cadorna is an acousmatic ambisonics composition, here presented for simplicity as a stereo reduction, based on manipulated recorded sounds.

Marshal of Italy, Luigi Cadorna (4 September 1850 - 21 December 1928) was an Italian General, Chief of Staff of the Italian Army during the first part of World War I. Under his command more than 750 men were executed on his watch. He firmly believed that the soldiers were just material to be sacrificed for the sake of the nation. Any failure was considered a lack of will. Officers were removed from their positions if they failed to carry out to the letter his absurd orders.

It is a matter of facts that no nation condemned and killed more of its own soldiers during World War I than Italy.

In memoriam Alessandro Ruffini (29 January 1893 - 3 November 1917) who could never go back home because of a cigar.

\section{REFERENCES}

Chion, M. (1991) L'audio-vision - Son et image au cinèma, Coll. Cinèma, Armand Colin, Paris.

Gerzon, M. (1975) Ambisonics. Part one: general system description. Studio Sound, 17, pp.20-22.

Schaffer, P. (1952) La recherche d'une musique concrète. Paris, Seuil.

Truax, B. (2018) Convolution Techniques.

https://www.sfu.ca/ truax/Convolution

Techniques.pdf (retrieved 14 February 2018). 